\section{Spain calls attention to EMBL}

SIR - The original concept that European molecular biology should attempt to emulate particle physics by trying to persuade governments to establish an international laboratory patterned on CERN (the European Laboratory for Particle Physics) crystallized in 1978 with the inauguration of the European Molecular Biology Laboratory (EMBL). Since then, EMBL has been renowned for high standards and scientific quality.

The rationale of such supranational projects relies on the assumption that either the development of science is too expensive for individual countries or that the whole is more than the sum of its parts and cannot be attained by individual countries. Although this probably holds for certain sciences, such as physics, it is not so clear that the same principle applies in biology. In fact, EMBL deals with the same things as national laboratories, approaching the same problems with the same tools, perhaps in grander surroundings.

The price that some of the member states must pay for the partnership is quite high. The budget of EMBL (see figure) is paid for by quotas based on the members' net national income (NNI) But three countries (Germany, United Kingdom and France) account for nearly 80 per cent of the benefits, as measured by the percentage of staff members. This illustrates the different attitudes of different member countries towards EMBL, as is clearly shown by Italy. Although it contributes 16 per cent of the EMBL budget, Italy had only five staff scientists in 1992. Spain's position is even worse - we contribute 7 per cent of the budget but have only one staff scientist.

This unequal distribution of benefits within EMBL was pointed out by the Italian delegation at recent meetings of the laboratory's governing council. And Spanish molecular biologists are asking whether it is reasonable to spend Spain's limited economic resources on an international laboratory without compensating advantages. This question is further stressed by the need for a country such as Spain, which is starting to make strides in science and technology, to have at home the best young scientists to boost scientific development. There are no simple answers, and clearly a substantial period (maybe 10 years) from our joining EMBL has to elapse before we can make a final evaluation.
This inequality needs attention, as the new EMBL director general seems to recognize. The problem now lies in the economic effort needed to implement his new initiatives, but the present economic recession makes things even more difficult.

We appreciate that science should be without borders and is international in its roots. Science requires international and multidisciplinary participation, but also the coexistence of differences. In that respect, science may even help to over-

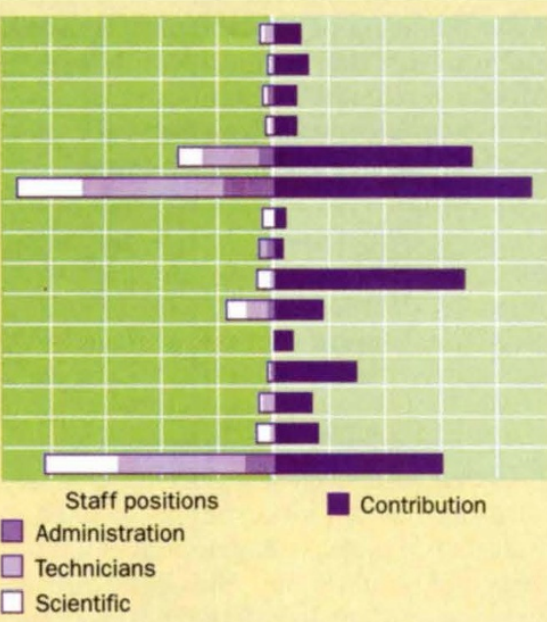

evels (left) compared to contrlbutions for come the present crisis in Europe, by demonstrating the virtues of cohabitation.

International institutes must therefore be favoured. This can be achieved only if, like a living organism, EMBL evolves to ensure its existence in such a way that it will not be contested either by administrators or by scientists. That requires an actual system of quotas, which from our point of view, should be based on the level of participation and not on NNI, and also on the general principle that nothing that can be done by member states individually would be repeated at EMBL.

Eladio Montoya

(Spanish delegates to the EMBL Council) Comisión Interministerial

de Ciencia y Tecnología,

Rosario Pino 14-16,

28020 Madrid, Spain

\section{Problems at CNR}

SIR - Crisis and chaos seem, unfortunately, to be endemic to Italian public institutions, and the Italian CNR (Consiglio Nazionale delle Ricerche) is no exception. We are writing to draw attention to the dismal plight of many postdoctoral research scientists within the CNR.
Carlos Martínez-A.
During the past four years, the average age of CNR researchers has increased and is now 45. This is because of a marked decline in the number of new research opportunities. Consequently, young career scientists, many trained within the CNR on CNR fellowships, are being forced to accept lower-level technician positions in order to pursue research and remain within the institution. There are some 170 scientists with doctoral degrees doing research at CNR facilities who have appointments at the technician level. Although their scientific productivity is comparable to that of CNR staff scientists or university researchers, they are paid much less and chances of promotion to positions commensurate with their qualifications, experience and productivity appear to be remote. This appalling situation is leading to growing frustration, apathy and resentment and threatens to exacerbate the debilitating atrophy that is crippling the CNR and the future of scientific research in Italy.

Surveys and letters in Nature ${ }^{1-3}$ over the past decade have drawn attention to inequities within the CNR and the urgent need for reform. Yet little has been done to improve the prospects for researchers, particularly younger scientists. We hope that the recent political changes in Italy will lead to radical changes in Italian science and we call upon Italian scientists, especially those in positions of influence, to press for immediate action. Our present situation is intolerable.

\section{Giovanni Agati}

Franco Fusi

Instituto di Elettronica Quantistica - CNR, Via Panciatichi 56/30,

50127 Firenze,

Italy

1. Walgate, R. Nature 303, 109 (1983).
2. Walgate, R. Nature 314, 489 (1985).

2. Walgate, R. Nature 314, 489 (1985).
3. Milne, R. G. Nature 361, 191 (1993).

\section{PiA grants}

SIR - May I draw the attention of those among your readers interested in clinical immunology to the 1993 Primary Immunodeficiency Association (PiA) research grants?

The PiA is the patient support organization and registered charity for those affected by primary immune deficiencies. In 1993, the PiA will be funding research again for its second year, when $£ 40,000$ has been allocated for projects in clinical immunology.

Further details and application forms can be obtained from me. The closing date for applications is 1 December 1993.

Robin J. H. Fanshawe

Primary Immunodeficiency Association,

POBox 1490,

Halstead,

Essex CO92SW, UK 